Conference: Community Engagement @ Your Library: Creating Vibrant, Diverse and Inclusive Communities

May 15, 2019

John Dewees, MLIS

Supervisor Digitization Services

Toledo Lucas County Public Library

\title{
LIBchat: Building Tools for Community-Driven Photo Collections
}

Good morning everyone, my name is John Dewees, and I work as the Supervisor Digitization Services at the Toledo Lucas County Public Library and I'm here today to talk a bit about getting your community involved by contributing to your library's local history collections. I started the Community Photo Album, or CPA for short, at my library last year with two goals in mind: to democratize our local history collection building by making our holdings as diverse and representative of our community as possible, and also to create a path by which our community gets to decide what is worthy of preserving, and not have the department acting as gatekeepers by picking the winners of what qualifies as "history" in our community.

The scope of the project is intentionally only photographs. Not diaries, not letters, not home movies, in order to keep things straightforward and to provide an easy means for the public to engage. People are frequently sharing photographs online anyways, we're just asking them to consider the library as a possible place to share as well.

Additionally, this makes digitization and metadata a much simpler process than the previously mentioned more complex objects. Each submission can contain up to five images.

The first uploads to the collection occurred in August of last year, and to date 1,285 images have been contributed. In the spirit of full disclosure, 741 of those images are actually photos that I myself have submitted, and hundreds more are photographs scanned by one of our local history librarians. These scanned photographs are generally donated photos that don't belong to a larger cohesive collection, and may not have been scanned as a result, as we tend to favor those larger projects.

Anecdotally, these sorts of local history programs soliciting content from the community can have pretty depressing engagement. The biggest hurdles generally are getting the public past a "oh that's sounds like a neat idea" reaction and to actually engage with the program after they are made aware of it, and also to believe that their materials are genuinely worth preserving at all. For those communities that are underrepresented in local history collections there are also well-deserved issues of trust, whereby they may feel they are literally giving up their history, and building that trust is not easy. I'm certainly not the first person to try such a program, and the general difficulty in gaining traction for this type of project very much informed how it was formulated. 
So my goal with the Community Photo Album was to design a lightweight and modular program. By lightweight I mean that there really wasn't much involved with getting this up on its legs. For digital images, there is a straightforward online form, powered by Jotform, that allows the images to be attached. For physical photographs, there is a near identical form fill-able PDF. Nothing more was required for the structure of the project. The legal agreement that those submitting agree to is short, written in as plain of English as possible, and designed to not be intimidating. So by modular I mean that the nature of the project was intentionally kept fairly open-ended so that this could be incorporated with other related programming, and so that different types of audiences could be invited to participate without needing to overhaul how this program functions from a workflow perspective.

In talking about the design of this project l'd also like to mention the importance of building variable target levels of success into projects from the start. If the CPA never received a single organic submission, there would still be a significant public good coming out of it, due to the number of images contributed by my coworker and I as a baseline, and the impact can only grow from there. This is important from a program planning point of view for a few reasons to me: if the intended larger goal of the project falls flat on its face, then I don't feel like the time and energy was wasted. This also realized a separate goal of getting oddball photographs scanned and finding a digital home for them. Finally, this project can be abandoned entirely for a given period of time, and getting it going again would take a trivial amount of effort. Resources can be devoted to it when it is a priority, or not when there are more pressing concerns, and the project as a whole is able to easily iterate and fail forward.

So I'm here to talk about outreach and engagement so I should probably discuss those at some point. I work with community organizations in the Toledo area to get their materials digitized and online, which is my primary outreach objective. Generally these are discrete projects; we scan a number of items, we get them online, we move on to the next project and partner. The Community Photo Album provides a channel for that relationship to be maintained after the end of the formal project, whereby I can encourage partners to continue to submit a handful of photographs from their archival materials periodically, or to document events happening inside their organizations in real time as they take pictures with their phones. This provides a useful basis for periodic check-ins with that partner by recommending use of the Community Photo Album as a means to continue their mission of preserving their history.

For me the even more exciting aspect of this project, is the ability to mix the CPA in with other programming opportunities and riding along on their outreach objectives. To give some examples, one community in which one of our branches sits lacks a senior center so the manager at that branch hosts what she calls a Silver Cafe to provide similar programming weekly or biweekly. Coffee and cookies are provided, a social outlet for the seniors is made available, and some sort of presentation is offered. She invited me in to present on this to her regulars who were interested in seeing photos of the area's 
history, and several were interested in a follow-up program where the branch manager could host a scanning day for their photographs.

Another branch library is doing a series of programs centered around photography of which I was invited to be one of the presenters, giving me the opportunity to talk about a larger issue of preserving our fragile digital images for posterity and providing an avenue by which they might be preserved. One of the other programs in the series is all about figuring out what to do with all those photos on your phone, how to store and edit them, and ensure they aren't lost. Some pretty easy synergies are immediately obvious.

A third branch library was interested in the idea of using the CPA as a submission avenue for art photographs, and holding a juried art exhibition at the branch in conjunction with area arts commissions and a regularly scheduled art walk. The photos submitted then get the robust digital preservation offered by our repository, as well as being published in Ohio Memory with information on the event, and any prizes they might win forever embedded in the image metadata. After the pilot phase of this we are discussing either making it a county-wide program, or a shared program for other branch locations to replicate (or both).

Finally, two branch libraries jointly asked me to present at a suburban Rotary Club meeting which is always looking for folks to come in and present on topics, which actually resulted in the first organic submission to the CPA.

So by working through the branch library network, I'm able to engage with an audience of seniors, and in a portion of the county I hadn't worked with yet, I'm able to engage with a general public interested in phone photography, I'm able to engage with creative types interested in the arts, and I'm able to engage with community partner organizations. These are all groups I may have considered reaching out to on my own but working through the branch libraries and their built-in community relationships ends up being a massive time-saver for me; I don't have to build those relationships from scratch, I just take advantage of the network, and a great deal of efficiency is created. By doing that internal networking and presenting internally at staff meetings and participating in shared programming committees, I'm able to then save time down the road.

So this is another formulation of a lightweight program, one that can be easily incorporated into other people's programming and thus able to reach the audiences they are already seeking to engage with instead of trying to form those paths from scratch. For those libraries here that have branch library networks, using them as your champions and doing robust internal networking, can be key to getting traction for projects. A lightweight program is easy for others to adapt, and see their own goals realized. For those libraries that don't have branches, the same approach can be taken with the area organizations that you likely already partner with. Also, generally speaking, this sort of interesting tinkering and combining of strategies is what I find most engaging, and keeps me thoroughly invested in my own work, and helps realize the 
Community Photo Album in ways that I could not have anticipated through the incredibly creative minds of my coworkers.

So aside from existing community partners, and branch library staff, the other avenue that I'm looking to focus outreach on is more traditional outreach to community organizations, but ones that aren't necessarily interested in realizing my local history goals, but might be interested in participating all the same, in this case camera clubs. Toledo has several clubs for hobbyist photographers who are already creating the exact content that I want to harvest. After attending my first meeting with one such group I was approached by a member who was interested in having someone from the library come in to present, and another, a retired professional photographer who was interested in finding a long-term home for all his negatives created in a lifetime of photographing Toledo.

For my presentation to this group I'm planning to discuss the Community Photo Album naturally, but also using our existing resources as the basis for "photography challenges" for the group. To start with, I plan to curate a collection of historical images of the area and then asking the club members to identify the exact spot the photograph was taken and recreate the photograph with a contemporary view. By asking the group to do something they are already interested in, I'm hoping I can convince them to meet my goals at the same time they are realizing their own.

In conclusion, my approach to outreach and engagement in the community I'm charged with serving is to not create unnecessary duplication of effort. Leveraging whatever network is available in order to move quickly has made my job much more seamless, particularly as I moved to the area last year and had no connections or network to speak of, this approach has allowed me to ramp up my efforts fairly quickly. Like most people here I'm sure, I wear a fair number of hats and outreach and engagement could pretty easily be a full-time job; this strategy has allowed that aspect of my position to be more manageable and more impactful. Thanks so much for listening and have a great conference. 